\title{
P78 Endothelial Dysfunction and Arterial Stiffness During Type 2 Diabetes
}

\author{
Maimouna Toure ${ }^{1}$, Magid Hallab ${ }^{2,}$, Souleymane Thiam ${ }^{3}$, Sheikh AB Mane ${ }^{1}$, Farid Belem ${ }^{1}$, Abdoulaye Samb $^{1}$ \\ ${ }^{1}$ Laboratory of Physiology Human and Functional Explorations, FMPO, UCAD, Senegal \\ ${ }^{2}$ Clinique Bizet, 75008 Paris, France \\ ${ }^{3}$ Laboratory of Biochemistry and Molecular Biology, OPCF, UCAD, Dakar, Senegal
}

\section{ABSTRACT}

Objective: We aimed to study Endothelial dysfunction and Arterial Stiffness in Diabetes mellitus.

Methods: 29 women with type 2 diabetes and 8 non-diabetic controls were included. Vascular function was studied with pOpmetre $^{\oplus}$ (Axelife SAS-France) to assess the foot to toe Pulse Wave Velocity; and EndoPAT2000 (ITAMAR-Israel) to measure endothelial vasodilatation dependent by measurement of reactive hyperhemic index (RHI).

Results: Diabetics were $56 \pm 6$ years vs $47 \pm 9$ years. Mean diabetes duration was $9.07 \pm 6.15$ years. RHI was normal in all controls $(1.94 \pm 0.68)$ and abnormal in $51.72 \%$ of diabetics $(1.83 \pm 0.12)$. An abnormal ftPWV was found in $38 \%$ of diabetic subjects $(11.6 \pm 7.7 \mathrm{~m} / \mathrm{s})$ vs $12 \%$ of controls $(7.7 \pm 2.3 \mathrm{~m} / \mathrm{s}$, normal $<10 \mathrm{~m} / \mathrm{s})$. There was a positive correlation between $\mathrm{ftPWV}$ and age $(r=0.25 ; p=0.001)$; $\mathrm{ftPWV}$ and duration of diabetes $(r=0.12 ; p=0.03)$. At the same time we found a negative correlation between RHI and fasting blood glucose $(r=-0.46 ; p=0.01)$, HbAlc $(r=-0.37 ; p=0.04)$, triglycerides $(r=-0.49 ; p=0.03)$ and total cholesterol $(r=-0.37 ; p=0.04)$. In a rapid and non-invasive way, we found endothelial dysfunction in $51.72 \%$ of diabetics and arterial stiffness in $38 \%$ of them.

Conclusion: During diabetes, endothelial dysfunction and arterial stiffness are therefore dependent on the glycemic balance, the duration of diabetes and lipid parameters. However, these two parameters appear independently and differently associated with diabetic disease.

(c) 2019 Association for Research into Arterial Structure and Physiology. Publishing services by Atlantis Press International B.V. This is an open access article distributed under the CC BY-NC 4.0 license (http://creativecommons.org/licenses/by-nc/4.0/). 